\title{
A SHIFT FROM “ME” TO “WE” IN SOCIAL MEDIA
}

Viktorija Lankauskaitè, Vilmantè Liubinienè, Kaunas University of Technology, Lithuania viktorija.lankauskaite@ktu.edu,vilmante.liubiniene@ktu.lt

\begin{abstract}
Currently media power is distributed via the multi-media World Wide Web. Web 2.0 has transformed every prosumer into an individual, mini-organism - "Me the Media" (the concept coined by Bloem, van Doorn \& Duivestein 2009). Recently a trend has started to emerge, which indicates that Web conversations are creating new power relationships. This is especially vivid in the current multi-media coverage of political events, supported by cross-cultural social activism. Thus, the aim of this study is to analyse the emerging new trends in current social media that embody the shift from "Me" to "We" in power relationships. The idea that everyone is inter-linked and inter-active on the Web, involving not only common citizens and politicians, but also companies or brands, supports the finding that "We the Media" is the next development in social media, which needs to be taken seriously and investigated on a wider scale.
\end{abstract}

Digital Age in Semiotics \& Communication, Vol. I, No. 1, Spring 2018, Pp. 51-61 
Keywords: Web 3.0; crowdsourcing; participatory culture; collective intelligence; digital culture; network society; media power; collective action.

\section{Introduction}

Contemporary media theorist and psychologist Sherry Turkle in her book "Alone Together: why we expect more from technology and less from each other" (2011) considers the question of how technology redefines human communication. If new technology denies direct communication, we come up against a problem - a huge amount of lonely, isolated people, crying for attention with the help of selfies. The book was published in 2011, and since then we have witnessed the great advance in technology development, together with the new modes of communication and new behaviour models emerging. Is the problem of loneliness and isolation still relevant in the contemporary networked society? Alongside the development of this software, undermining modern communication, it is possible to hypothesise that at least on social media a shift from the emphasis on "Me" (the inner self-isolation) is occurring towards the emphasis on "We" - the community, which focuses its attention on participation and solving common problems or initiation and implementation of joint ideas in action. To test this hypothesis, our research aims at analysing the emerging new trends in the current social media which embody the shift from "Me" to "We" in several areas. In order to accomplish the aim, the following objectives have been set: to analyse the changing context of contemporary digital culture; to discuss the model of online self-identification, concentrating to the shift from Ego to Hyper Ego; to provide interpretation for the shift from "Me" to "We" based on the research of media content and emerging patterns in communication.

In order to research new patterns in communication, we have employed netnography as the research methodology. Netnography is a term coined by Robert V. Kozinets (2002) to describe the use of online marketing research techniques to gather information about the way individuals behave and interact in the cybersphere. It has evolved from ethnography, a widely used research methodology in the field of cultural studies, perceived as a qualitative understanding of cultural activity in context. Nowadays ethnography, as outlined by Barker and Jane (2016: 39), becomes less an expedition in search of 'the facts' and more a conversation between participants in a research process: "Ethnography now becomes about dialogue and the attempt to reach pragmatic agreements about meaning between 
participants in a research process" (Barker and Jane 2016: 40). Nowadays, in the context of media-oriented cultural studies, ethnographic techniques are increasingly being used to investigate the ways communities and cultures work online and on social media platforms. Thus netnography, or ethnography on the Internet, is a new qualitative research methodology that adapts ethnographic research techniques to the study of cultures and communities emerging through computer-mediated communications. As outlined by Kozinets, (2002) "netnography uses the information publicly available in online forums to identify and understand the needs and decision influences of relevant online consumer groups. Compared to traditional and market-oriented ethnography, netnography provides researchers with a window into naturally occurring behaviours, such as searches for information by, and communal word-of-mouth discussions between, consumers" (Kozinets 2002).

The structure of this paper develops along the following lines: analysis of the contemporary digital culture, including an overview of the prosumer society, participatory culture, crowdsourcing, collective intelligence, etc. and the discussion of emerging new trends in social media, which embody the shift from "Me" to "We", finalised by conclusions.

\section{Analysis of factors, initiating the changes in contemporary digital culture}

Contemporary digital culture acquires a variety of new features; to name a few, it could be referred to as "Digital Culture", "Visual Culture", "Participatory Culture", etc. All these concepts have evolved as a result of developing contemporary media technologies which permeate our everyday life and cultural environments.

New media, without having a long history behind it, is always in the process of development. The fact that more and more people use social media makes the subject relevant and important to research. Much of current research focuses on the direct impact of social networks, both to individual, and communities, as well as to the development of social media itself. However, the impact observed is more psychologically, socially, and behaviourally based.

As electronic communication emerged, its impact on the society became evident when people appeared to be more and more involved in the networking. The term "Network Society", first used by Jan van Dijk (De Netwerkmaatschappij (1991) (The Network Society)), later by Manuel Castells (The Rise of the Network Society (1996)), can still reflect the sit- 
uation of the society today, even if the means of communication and the devices are more advanced. Castells claims that the devices, and currently developed new social networks, in this case social media, influence the behaviour in the everyday society because of information management. "... The definition, if you wish, in concrete terms of a network society is a society where the key social structures and activities are organized around electronically processed information networks. So, it's not just about networks or social networks, <...> It's about social networks which process and manage information and are using micro-electronic based technologies" Castells (2010). This assumption reflects what is exactly happening today. People might unconsciously behave according to the information they receive on the web. The information is filtered out by certain parameters, according to previously made choices, as searches, clicks, or "like" buttons are hit. Then, the web offers one or the other option according to the past activity and influences the following behaviour both online and in reality, when it comes to advertising, event promotion, and social involvement. We tend to use and attend the things we are used to seeing.

Along those lines, it is also worth mentioning Lev Manovich (2013), and his book "Software Takes Command". Software within social media, its developments and improvements allows for the surveillance of a user's every online step, and for the influence of the future behaviour there. The impact of software being a part of our daily lives lies not only in the improvements of user interface, or general layout of the web environment, but also on how advanced the web itself is. The algorithms used for content delivery and promotion, or determining patterns of interest through searches, most visited sites, or general activity on the web are not a novelty these days. They allow to create networks of people, groups, masses with the same interests, goals, or working for the same cause, from all over the world.

Discussion about the internet, especially Web 2.0, is impossible without mentioning the participatory culture. Henry Jenkins, the Professor of communication, journalism, and cinematic arts at the University of Southern California has made the greatest impact in defining and promoting the concept of participatory culture. By "participatory culture" he means a form of culture in which the media users act not only as consumers, but also as producers. He calls them prosumers. The term is most often applied to the production or creation of some type of published media. Recent technological advances have enabled private persons to create and publish such media, usually through the Internet. This new culture as it relates to the Internet has been described as Web 2.0. Further on, Jenkins elaborates on convergence culture - the combination of new media and old media 
within a single piece of media work - the coming together of different media products/technology (Jenkins 2006).

Another important concept, coined by Jenkins, which is very much important in understanding the digital culture is collective intelligence. Collective or group intelligence, as defined by Jenkins (2006), emerges from the collaboration, collective efforts, and competition of many individuals and appears in consensus for decision making.

"None of us can know everything; each of us knows something; we can put the pieces together if we pool our resources .... Collective intelligence can be seen as an alternative source of media power" Jenkins (2006).

Jenkins' conception of media convergence, and in particular convergence culture, has inspired much scholarly debate. Jenkins argues that convergence represents a fundamental change in the relationship between producers and consumers of media content.

Fuchs (2017), writing about the three forms of the web's sociality (cognition, communication, and cooperation), speaks about the change of interaction on the web from Web 1.0 to Web 2.0 to Web 3.0. According to him, all three forms are intertwined and depend on each other, but he also admits that a change is present. "The three forms of Sociality (cognition, communication, cooperation), are encapsulated into each other. Each layer forms foundation for the next one, which has new qualities" Fuchs (2017). These "new qualities" are what we have now on the web and in society, different kind of communication, cooperation, the need and willingness to participate and contribute to the pool of intelligence and resource. Cognition alone is not enough, but it is not absent either.

John Moravec (2008) believes that a new paradigm for 21 st century education will change the way teaching is perceived. If in the environment of Web 1.0 the teaching was solely concentrated on communicating the knowledge in one direction - teacher to student, in Web 2.0 it develops both ways - teacher to student and student to student, and finally in Web 3.0 the interaction involves not only teacher to student and student to student, but student to teacher. This brings to the conception of crowdsourcing as "a practice of obtaining needed services, ideas, or content by soliciting contributions from a large group of people and especially from the online community rather than from traditional employees or suppliers" (Crowdsourcing in Merriam Webster dictionary, 2011). Thus, crowdsourcing aligns with the idea of the need for a bigger online community to achieve certain goals, therefore one cannot be alone anymore once one is connected online. Nowadays, the simplest example could be Q\&A platforms, where one person asks a question, and the community on the web tries to answer it as 
best they can, based on their experience and knowledge. That way, the one who asked the question gets more information from different sources and has many more chances of getting the proper answer.

Among other scientists, Viktor Mayer-Schönberger and Kenneth Cukier in their book "Big data - the essential guide to work, life and learning in the age of insight" (2017) refer to Big data as to "things one can do at a large scale that cannot be done at a smaller one, to extract new insights or create new forms of value, in ways that change markets, organizations, the relationship between citizens and governments, and more" (Mayer-Schönberger \& Cukier 2017: 6). In a way they also predict the change in the relationship between citizens as the collectivity, contributions which may bring about major transformations. Further on, they concentrate on description of the three major shifts of mindset: "the first, is the ability to analyze vast amounts of data about a topic rather than be forced to settle for smaller sets. Using all the data at hand instead of just a small portion of it. From some to all. $\mathrm{N}=$ all. The second is a willingness to embrace data's real-world messiness rather than privilege exactitude. The third is a growing respect for correlations rather than a continuing quest for elusive causality" (Mayer-Schönberger \& Cukier 2017: 19).

All the theories and studies briefly discussed in this section clearly illustrate the shift from "Me", the user of the web, the consumer of the information, to "We" - prosumers who are collaborating, creating, and sharing the content. This trend is particularly in line with Jenkins' ideas, and is supported by other authors as well.

Analysing this trend, it is also important to concentrate on the issue of virtual prosumers' identities. It could be observed that some studies aim to research "Me-Media" dynamics (Bloem, van Doorn \& Duivestein 2009), while others discuss the conditions of multiple identities enacted in Multi User Dimensions (Turkle, 1995). For Turkle, the multiplicity and heterogeneity of online identities is rooted in the new social experience of postmodern culture. Barker and Jane (2016: 265) note that "the decentred or postmodern self involves the subject in shifting, fragmented and multiple identities. Persons are composed not of one but of several, sometimes contradictory, identities". In this "Me-Media" dynamic, composites of digital alter egos are rapidly becoming an accepted form of personal and brand identity. They increasingly form the basis for the social and economic activity in which individuals, organizations, and government engage. As Bloem, van Doorn \& Duivestein 2009 note, "the third media revolution emancipates physical identities to the "Hyperego" level: the digital Me's all 
are hyperlinked and super active on the Web, involving citizens, brands, companies and politicians" (Bloem, van Doorn \& Duivestein 2009:14).

As the aim of this study is to test the hypothesis that a shift from the emphasis on "Me" to the emphasis on "We" (the community) is visible in social media, the second part will deal with the analysis of different cases, selected according to the methodology of netnography and illustrating the emerging trend in the current social media.

\section{Analysis of the emerging new trends in social media, which embody the shift from "Me" to "We"}

Following the principles of netnography, several cases will be analysed and discussed in detail, illustrating the trendy shift from the individual to the collective action in social media.

The interface of social media networks itself allows for assumptions that it was designed for crowds to use, for masses to engage in one or other activity online. First of all, the existence of the Newsfeed could be discussed, as it is now one of the most significant features of social media. Introduced on Facebook in 2009, it soon reached other social media platforms such as Twitter, Instagram, and others. This feature allows seeing changes made by people in the friends list on Facebook, whether it would be a life event or an ordinary update. Previously seen as a breach of privacy, now it is adopted by many users and rarely questioned.

Furthermore, developments or User Experience features like "like", "follow", "share", "subscribe" or buttons of similar origin, presumably encourage participation and connection with others that hold similar interests. By clicking one or the other button, social media users assign themselves to one or the other group, a so-called segment of interests that might be later used for advertising, research, or general reach purposes, sometimes unknown to the users.

Another development that is widely used, appearing less as an automatic process and more as something actively adopted by the user, is the use of hashtags, tagging, and commenting. The users themselves choose which hashtag to use or whether to use it at all. Tagging might be more intrusive because one user can be tagged on photos or posts by other users, but the one tagged now has an option to remove the tag without any repercussions. The other possibility, commenting, permits users to engage each other in public discussions, confirming their interest in a particular topic, or the need of the discussed matter to be at the top of the Newsfeed. 
All these features are directly connected to the Newsfeed, because the more attention a post gains, the more likely it is to stay at the top of the page for the longer time. Every like, share, comment, or follow expresses the approval of the crowd on the web, the social media users. This is where the collectiveness becomes evident; one or two likes is nothing compared to two or three thousand.

The following cases can show the power of those developments, and how groups of people across the web create trends that help them to stay visible and followed, and how "Me" on social media shifts to "We".

\subsection{Illustration of the power of crowdsourcing (Case 1).}

Laisves TV (EN - Freedom TV) an alternative internet TV channel started in Lithuania, joined Facebook on 28 Aug 2016. First TV show was streamed on 11 September 2016 on YouTube (https://www.youtube.com/ channel/UCMfPBtm9CWGswAXohT5MFyQ/about). The channel had 157 videos (by 29 August, 2017). By the time of 29 August, 2017 it held the number of 47,316 subscribers, and the most popular video had 9,237,401 views. The show is so popular, some of the episodes have been made in Russian as well.

It is an internet television channel based only on open code. The shows are streamed on YouTube, but despite the premise it is still professional and of high quality. Television production professionals and experienced specialists also contribute to the production of several different TV Shows, broadcasted on the same channel. Apart from being non-profit television production, it aims at the viewers as the ones who know what they want to see most. Again, each "like" (22,819 people like and 23,352 people follow the page as of 30-08-2017, (https://www.facebook.com/laisvestv/) on Facebook page, or Subscribe click, acts as an approval of the content. The viewers are not only invited to watch the content, they are also able to contribute both financially and creatively. Financial contributions are made on Patreon, a sponsoring platform where individuals can donate money and directly support the project. Currently Laisvès TV has 4,423 patrons, and gains $\$ 15,389$ per month Patreon.com (http://www.patreon.com/laisvestv 30-08-2017). This is one of the best examples of crowdsourcing, the TV channel is the only one in the world supported exclusively by its viewers. Laisvès TV also stresses the importance of not allowing the big corporations to support them, because they want to preserve complete objectivity, and no influence on the content. The example of this channel, now a platform of addressing various issues of the wider community shows that the 
community itself can be responsible for the content it receives and, moreover, that the contributions of each single member, through crowdsourcing practices, can create something powerful and worthwhile, convincingly indicating that Social Media is a place for crowds and collectivity to flourish.

\subsection{Practical implementation of participatory culture (Case 2)}

"Putvinskio gatvès diena" (EN - Putvinskis street day) http://www. vdu.lt/lt/ivykiai/renginys-putvinskio-gatves-diena/ announced on 27 May 2017 is an event dedicated to one particular street in the city of Kaunas, Lithuania. The citizens of Kaunas were invited through social media to join and spend some time with their neighbours enjoying conversations, social, educational activities as well as to explore what that street has to offer. The interesting thing is how social media and activity on the web urged the people to get out of their houses and join the live conversations with the people they live close by. This illustrates how, though social media users may be "alone together" Turkle (2011), participation on the web brings some part of that collectiveness into the real world as well.

Another illustration triggering participation is related to the joint composition of the Lithuanian coat of arms used as a decoration on the car of a well-known racing car driver Benediktas Vanagas who participated in the Dakar rally in 2017. He has used his social media profile and invited his fans to participate together, at least virtually, by creating a big collage of photos that would make up a Lithuanian coat of arms - Vytis. People were able to click a link on his Facebook page, which would take them to a webpage allowing to upload a photo. The photo then appeared among thousands of other photos, together creating a silhouette of a horse and a knight riding it. A car sticker was made which later decorated the car and was kept through the Dakar ride of Benediktas Vanagas.

This shows the Social Media Network to be an outlet that not only allows informing people of the option to participate (the driver still shared photos and videos from the site, kept the fans up to date), but also to take a part in symbolic car-race as the member of community signifying the belonging to the state that the driver represents. Through Social Media people were able to virtually join the race, and become "Them" on the web, instead of only "Him" alone - the driver.

\subsection{Collective intelligence in action (Case 3)}

The power of internet seems to be more and more important to the various creators of media content, especially artists, when they search 
for inspiration or for something to build their work upon. A tool, called Hit-Record, was established by a well-known actor, Joseph Gordon Levitt, to bring artists together for collaboration. A creator (a writer, actor, painter, filmmaker, singer, etc.) can upload his or her product on the web for other artists to use for their creations. All of the work that is submitted becomes open source and anyone that belongs to the platform can dispose it. For example, if there is a writer who submits a poem, a singer can take it, and record a song with the lyrics of the poem. Then later, a filmmaker can take the recording and use it as a soundtrack for the film. Any kind of similar collaborations and exchanging artwork is possible and encouraged. The platform is a great example of reaping the benefits of collective intelligence to create the best work possible, because it might be so, that one creation is much better in a different form and seen through somebody else's eyes, and HitRecord permits exactly that.

\section{Conclusions}

1. Emerging new trends in social media are related to the shift in a semantic paradigm, which consists of a transfer of the emphasis from "I" - individual achievement, goal attainment, individualism, to "WE" - Web 3.0, crowdsourcing, participatory culture, collective intelligence, etc

2. Rapid and overwhelming technological development paves the way for the current changes - the shift from individualism to collective actions on the web.

3. A observed shift from communication to cooperation which enables joint actions to be translated into real mass activism. 


\section{References}

Barker, Chris \& Jane, Emma A. 2016. Cultural studies theory and practice. London: Sage Publications Ltd.

Bloem, Jaap; van Doorn, Menno; Duivestein, Sander. 2009. Me the Media: Rise of the Conversation Society. Kleine Uil, Uitgeverij.

Castells, Manuel. 2010. The Rise of The Network Society: The Information Age: Economy, Society and Culture. Wiley.

Crowdsourcing. 2011. In Merriam-Webster dictionary (last accessed October 20, 2017, from https://www.merriam-webster.com/dictionary/ crowdsourcing).

Fuchs, Christian 2017. Social Media - A Critical Introduction. UK: Sage.

Jenkins, Henry. 2006. Convergence Culture: Where Old and New Media Collide. New York and London: New York University Press.

Kozinets, Robert V. 2002 The Field Behind the Screen: Using Netnography For Marketing Research in Online Communities. Journal of Marketing Research Vol. XXXIX (February 2002), 61-72

Manovich, Lev. 2013. Software Takes Command. New York: Bloomsbury.

Mayer-Schönberger,Viktor; Cukier, Kenneth. 2017. Big data: The essential guide to Work, Life and Learning in the Age of Insight. London: John Murray Publishers.

Moravec, John. 2008. Toward Society 3.0: A New Paradigm for 21st century education. (last accessed October 20, 2017 from https://www. slideshare.net/moravec/toward-society-30-a-new-paradigm-for-21stcentury-education-presentation).

Turkle, Sherry 1995. Life on the screen. New York: Simon \& Schuster.

Turkle, Sherry 2011. Alone Together: Why we expect more from Technology and less from Each other. UK: Hachette.

Van Dijk, Jan. 1991. De Netwerkmaatschappij (The Network Society). Houten, The Netherlands: Bohn Staflen Van Loghum. 